\title{
A Brief Analysis of the Integration of Female Subjective Consciousness Education into the Ideological and Political Work in Colleges and Universities
}

\author{
Qing Peng, Wenxin Zhu \\ Ningbo Polytechnic, Ningbo, Zhejiang, China
}

\begin{abstract}
Female subjective consciousness education is an important content in the ideological and political work in colleges and universities, and is an organic part of college and university's fundamental task of establishing morality and educating people. Clarifying the female subjective consciousness education in the ideological and political education in colleges and universities is conducive to the cultivation of builders and successors of the socialist cause who develop in morality, intelligence, body and aesthetics. This paper intends to sort out the current situation of the integration of female subject consciousness into ideological and political education in universities, analyze the significance of the integration, and put forward the countermeasures of the integration from following five aspects: colleges and universities should adhere to the guidance of the basic principles of Marxism in its ideological and political education work; enrich and improve the ideological and political education system in colleges and universities; strengthen the female subjective consciousness education among teachers; promote the education of female subject consciousness in accordance with local conditions; and constantly radiating the signal of the female subjective consciousness education to the society.
\end{abstract}

Key words: female subjective consciousness; ideological and political education; colleges and universities

\section{Introduction}

President Xi Jinping once delivered an important speech entitled "Promote Women's All-round Development and Build a Better World" at the Global Summit of Women. In the speech, he pointed out that "men and women share a world, the elimination of discrimination and prejudice against women will make society more inclusive and dynamic. We should strive to eliminate all forms of violence against women, including domestic violence. With gender equality as the core, we should break the outdated concepts and stereotypes that hinder women's development. Higher education, shouldering the important task of training the socialist cause's builders and successors who are morally, intellectually, physically and aesthetically developed in an all-round way, and must cling to the correct political direction. The foundation of a college's life is to cultivate people by virtue." Therefore, the fundamental task of educating people with morality necessarily include the all-round development of equality between men and women. The all-round development of equality between men and women stems from people's deep understanding of the relationship between men and women and their realistic situation, while education is the inevitable way to improve this understanding. As the cradle of a high-level talents training, colleges

Copyright (C) 2020 by author(s) and Frontier Scientific Research Publishing Inc.

This work is licensed under the Creative Commons Attribution International License (CC BY 4.0).

http://creativecommons.org/licenses/by/4.0/ 
and universities are bound to shoulder this task and integrate the relevant education into the existing ideological and political work system.

\section{The Connotation of Female Subjective Consciousness}

In the current society, women are still in a weak position. To realize the all-round development of equality between men and women, it is inevitable for women to awaken themselves and enhance their subjective consciousness. Then, what is "female's subjective consciousness"? Specifically, female subjective consciousness means that women can consciously realize and fulfill their historical mission, social responsibility and life obligations, clearly know their own characteristics, and participate in social life in a unique way, so as to affirm and realize their social value and life needs. With the continuous change of the times and the continuous evolution of social environment, the content of female subjective consciousness should also keep changing. In the period of contemporary social transformation, female subjective consciousness becomes much stronger and more abundant than any previous period. It is mainly manifested in the aspects such as the consciousness of rights, the consciousness of independence, the awareness of sustainable development and the sexual awareness.

\section{Present Situation of Gender Differences and Female Subjective Consciousness}

As far as family education is concerned, parents have been intentionally or unintentionally creating a family atmosphere of different genders. The author combed through the list of previous grade's students and found that a considerable number of girls' names contained keywords such as Yanan (means sub male), Jingnan (means competing with male). In addition, if a boy's name has a feminine connotation, he will be wildly discussed by students around him. Through the connection between home and school, the author found that in many parents' concept, "boys are Construction Banks, while girls are Industrial and Commercial Banks", that is, boys' parents have to work harder and plan for the boys' future, while girls' parents have no such burden psychologically at least. In addition, in our daily life, gender differences widely exist in the aspects such as the values, the manners of getting along with people, personal images and so on. For example, girls are generally asked to be quiet, gentle and reserved from childhood, while boys are generally taught by parents to be proactive, outgoing and pay for girls and so on. Gender differences are more obvious in the mate selection. Males are often reluctant to accept females who are higher than themselves in terms of social status, educational background and social experience.

For most students, high education is the last systematic education before they step into the society. So the deficiency of gender education in family education makes it more important for colleges and universities to integrate the female subjective consciousness education into the ideological and political education work.

In terms of social atmosphere, on a macro level, social evaluation system tend to be not friendly to female. For example, to judge a woman is successful or not will mainly consider her family factors, while the evaluation criteria for a successful man are more prone to his social status and income. Moreover, for some outstanding women in society, the media still habitually call them Mr. XX. In the middle sense, females are still in a disadvantageous position. For example, in the employment stage, under the same conditions, males are generally much more likely to be employed than females, and enterprises have not evaded the reason. They generally believed that giving birth and dealing with family affairs will take women more time and energy. In the mass media, female roles are usually stereotyped as housewives, and female's gender often becomes a eye-catching gimmick in films and television works. In addition, in recent years, the campus online loan has been a lingering nightmare for colleges and universities. While in the campus naked loan, which accounts for the considerably large proportion in campus online loan, the female college student can obtain loans by holding her own ID card nakedly. The behavior itself is to equate female gender with money, which is just a manifestation of the lack 
of female subjective consciousness. On the micro level, women themselves often carry some biased labels, but they themselves "voluntarily" accept it. A typical phenomenon is the so-called "female driver" phenomenon. In the society, there are endless jokes to mock up female drivers. In these arguments, female drivers are synonymous with disorderly driving, not knowing the road and causing more accidents. However, according to the statistics of traffic management departments, the accident rate of male drivers is much higher than that of female drivers in different regions over the years. Faced with such ridicule and banter, the female voice seemed insignificant.

The education of female subjective consciousness in colleges and universities needs to stand on the ideological level of "community with a shared future for mankind", shoulder the responsibility given by history, and let more people realize that the importance of arousing female consciousness is not only because women account for half of the total human population, but also because the spiritual culture of human beings in the past was based on the suppression of women and constructed a system of keeping female in the "inner room". Nowadays, eliminating this oppression and imprisonment, and reevaluating and correcting them from the perspective of female may reconstruct a new human civilization based on the new complementarity between males and females.

\section{The Status Quo and Significance of Integrating the Female Subjective Consciousness}

\section{Education into the Ideological and Political Work in Colleges and Universities}

As far as the university itself is concerned, the curriculum for women's education is not very independent of the relevant courses. The social practice of gender equality depends on the theoretical support in other disciplines and academic fields. The influence of course is weak, and the related courses are generally offered in the form of optional courses or lectures, lacking of core competitiveness. As far as the curriculum evaluation is concerned, the evaluation of female education curriculum basically adopted the method of examination. However, passing a certain female education course examination does not mean that the female subjective consciousness has been cultivated in its right place. In addition, gender prejudice is still common, and even persistent. Arguments such as "better to marry-well than do-well in exams", "this major is not suitable for girls", have always been heard in the campus. In essence, these views are still artificial regulations or even negation imposed on women from the perspective of patriarchal society. The long-term existence of these views has gradually become a kind of gender awareness and a conventionalized rule. Even women themselves do not realize that this is a kind of differential treatment, and consciously accept it in a subtle way, so few people would reflect it and much less to raise doubts toward it.

It is of great significance to incorporate women's subjective awareness education into the work of ideological and political education in colleges and universities. On the one hand, it boosts the theoretical development and improvement of feminine disciplines, on the other hand, it aims to arouse the female subjective consciousness, so as to help students realize that women should have an independent personality, rather than the existence of "second nature". On the other hand, it helps students master a certain theoretical weapon of female subject consciousness. In this way, students can re-recognize their gender and re-establish a truly equal relationship between genders.

\section{The Countermeasures of the Integration of Female Subjective Consciousness into} Ideological and Political Education in Colleges and Universities

First, as for the choosing of methodology, we should always adhere to the guidance of the basic principles of Marxism. Colleges and universities are the important departments in the field of ideology. Persisting in Marxism occupying the ideological front in colleges and universities is the ideological guarantee for adhering to the direction of socialist education. The female subjective consciousness education, as a part of the ideological and political education in colleges and universities, must adhere to the guidance of the basic principles of Marxism, and resolutely prevent the overflow and 
spread of western extreme feminist thoughts in colleges and universities. In Marx's works, he profoundly pointed out that "The relationship between man and nature, between man and man, and between man and woman, determine the degree to which human beings evolve from natural behavior to human behavior, from human essence to natural nature, and from human nature to human behavior." From this relationship, we can judge the whole process of one's upbringing and the extent to which one becomes and understands oneself as a human being. Adhering to the guidance of the basic principles of Marxism is the powerful theoretical weapon of female subjective consciousness education in colleges and universities.

Second, the ideological and political education system should be constantly enriched and improved. Colleges and universities should attach great importance to the integration of female subjective consciousness in ideological and political education. In the top-level design of teaching content, the education of female subjective consciousness should be included in the teaching plan and policies should be guaranteed. The important role of ideological and political theory teachers and instructors should be given full play, and the education of female subjective consciousness of college students should be strengthened. On the one hand, female subjective consciousness education should be brought into the teaching of ideological and political theory courses in colleges and universities, and it is advisable to organize teachers to compile relevant learning materials, so as to change the situation that the courses of female subjective consciousness education is fragmented, and even no available teaching materials. On the other hand, colleges and universities should try to increase and stipulate clearly the content of female subjective consciousness education in the daily ideological and political education.

Third, the education of female subjective consciousness of teachers should also be strengthened. General secretary Xi Jinping once stressed at the National Conference on Ideological and Political Work in Colleges and Universities: Teachers, who are the engineers of human soul, bear a sacred mission to disseminate the beliefs. The teacher, also the "preacher", must first be clear about the beliefs and believe in it. Teachers in colleges and universities should insist that educators should be educated first and strive to become the disseminators of advanced ideology and culture as well as the firm supporters of the Communist Party's governance, and better shoulder the responsibility of guiding and leading the healthy growth of students. As the first person responsible for the education of female subjective consciousness in colleges and universities, teachers themselves should be "enlightened and faithful", and then "preach" by example to conduct positive guidance. Therefore, colleges and universities should incorporate the female subjective consciousness education into the teacher's training plan, and constantly improve the female subjective consciousness of teachers.

Fourth, to promote the education of female subjective consciousness in accordance with local conditions. The education of female subjective consciousness in colleges and universities is not only allows teachers and students to theoretically understand the content of female subjective consciousness, but also guides teachers and students to practically use theory to guide their own activities. On the one hand, teachers themselves should constantly strengthen their own theoretical cultivation, and be able to comprehensively describe the female subjective consciousness in classroom teaching. On the other hand, we should make students feel the extreme importance of female subjective consciousness via various forms of internship and practice.

Fifth, to radiate the signals of female subjective consciousness education to the society constantly. It is an arduous task and a long way to go to deepen the education of female subjective consciousness as well as to promote the awakening of female subject. It is far from enough to rely solely on statements made at colleges and universities. Although colleges and universities have a strong reserve of talents, intellectual support, and their own influence, they have unique advantages in ideological guidance, but while giving full play to their ideological guidance, they must make full use of various resources to continuously radiate positive signals of female subjective consciousness education to the society and families, 
and strive to create a big pattern of boosting the female subjective consciousness education with the coordination of the three party -- "School-Family-Enterprise".

\section{Conclusions}

At present, the education of female subjective consciousness is relatively weak in the ideological and political work of colleges and universities. Thus, colleges and universities should make full use of their own advantages, lead the thinking, and strive to build a new mode of female subjective consciousness education, and earnestly shoulder the fundamental task of moral education in colleges and universities, and cultivate qualified "builders and successors" for socialist construction.

\section{Conflicts of Interest}

The author declares no conflicts of interest regarding the publication of this paper.

\section{References}

[1] Xi J.P. (2015). Promote Women's All-round Development and Build a Better World. People's Daily.

[2] Xi J.P. (2016). The Foundation of a College's Life is to Cultivate People by Virtue. Xinhua Daily Telegraph Edition 1.

[3] Fu X. and Wang S.F. (2005). The Subject Consciousness of Contemporary Chinese Intellectual Women in Awakening and Growing up, http://eladies.sina.com.cn/nx/2005/0603/1102164424.html.

[4] Yang H.M. (2002). Female's Subjective Consciousness in the Period of Contemporary Social Transformation. Journal of Pengcheng Vocational University, (1): 27-30.

[5] Chen D.P. (2017). A Rustic Opinion of Female Consciousness Education in Ideological and Political Education in Colleges and Universities. Education and Teaching Research, (12): 27-31.

[6] Liu Q.H. (2013). Firmly Occupy the Position of Colleges and Universities with Marxism. Tibet Daily.

[7] Karl M. and Frederick E. (1979). Karl Marx and Frederick Engels. People's Publishing Press, Beijing, (42): 119.

[8] Ma Y.Z. (2017). Understanding, Believing and Preaching the Truth. Guangming Daily. 